\title{
La gastronomía en la prensa española del siglo XIX
}

\author{
Ainhoa Aguirregoitia Martínez \\ Universidad de Alicante \\ aguirregoitia.ainhoa@gmail.com \\ María Dolores Fernández PoyATOS \\ Universidad de Alicante \\ dolores.fernandez@ua.es
}

Recibido: 11 de junio de 2014

Aceptado: 8 de enero de 2015

\section{Resumen}

En esta investigación, se ha analizado la gastronomía en la prensa española del siglo XIX a través del catálogo online de la Biblioteca Nacional. Los resultados, casi todos inéditos, revelan la importante presencia de la gastronomía en noticias, artículos y reportajes, y su desarrollo a partir de 1860, pero sobre todo en las dos últimas décadas de la centuria. Igualmente, ha sido posible plantear una categorización, así como esbozar parte de su historia y evolución en España.

Palabras clave: gastronomía, periodismo, siglo XIX, historia, publicidad.

\section{Gastronomy in the Spanish Press during the $19^{\text {th }}$ century}

\begin{abstract}
In this investigation, the gastronomy in the Spanish press during the 19th century has been investigated though the online catalogue of the National Library. The results, most of them unpublished, reveal the relevant presence of the gastronomy in the news, articles and reports, and its development from 1860 on, but mostly during the last two decades of the century. Additionally, it has been possible to outline a categorization, as well as drafting part of its history and evolution in Spain.
\end{abstract}

Keywords: gastronomy, journalism, $19^{\text {th }}$ century, history, advertising.

\section{Referencia normalizada}

AGUIRREGOITIA MARTÍNEZ, Ainhoa y FERNÁNDEZ POYATOS, Ma Dolores (2015): "La gastronomía en la prensa española del siglo XIX". Estudios sobre el Mensaje Periodístico. Vol. 21, Núm. 1 (enero-junio), págs.: 17-33. Madrid, Servicio de Publicaciones de la Universidad Complutense.

Sumario: 1. Introducción; 1.1. Fuentes y metodología. 2. A propósito de los términos gastronomía, culinario, coquinario. 3. El discurso gastronómico en la prensa del siglo XIX; 3.1. Historia de la gastronomía; 3.2. Teoría gastronómica; 3.3 Publicidad; 3.4. Recetas; 3.5. Curiosidades. 4. Conclusiones. 5. Referencias bibliográficas.

\section{Introducción}

Hasta hace apenas una década, el interés por la gastronomía en España ha sido escaso, centrándose la mayoría de la producción editorial en recetarios y noticias muchas veces de ámbito regional y local. Sin embargo, desde 1970 y sobre todo a partir de la notoriedad alcanzada por renombrados cocineros -su buen hacer y su labor divulgadora-, los temas gastronómicos ocupan cada vez más espacio en los medios de comunicación, así como en la investigación académica.

A mayor abundamiento, los estudios históricos europeos sobre la alimentación y la gastronomía han arrinconado injustamente el papel desempeñado por España 
(Simón, 1997: 125), insistiendo en un largo desconocimiento que comenzó a cambiar desde la puesta en marcha de investigaciones como las que detalla Pérez Samper (2009: 105-162) y de proyectos como el de la Biblioteca Universal de Gastronomía, iniciado en 1997 y en el que participa entre otras entidades la Real Academia Española de Gastronomía, y cuyo fin ha sido el de catalogar y crear una gran base de datos para la localización de todos los ejemplares, manuscritos o impresos de contenido alimentario (y afines), aparecidos hasta el 1900, así como los más importantes publicados con posterioridad.

El desinterés referido ha producido curiosas paradojas como la de ignorar que en nuestro país las obras sobre alimentación y gastronomía llegan a equipararse en volumen a las de países líderes como Francia e Italia: hasta el año 1900 se han catalogado más 700 ejemplares, que representan tan solo un tercio de lo publicado (Simón, 1999: 27); de lo que se concluye su gran riqueza, pero también el gran desconocimiento de nuestra cultura gastronómica. De alguna forma, esta cifra tan abultada debió tener su correlato en el medio de comunicación por excelencia del siglo XIX: la prensa, de ahí el interés de comprobar si en efecto la gastronomía era ya entonces un tema que rebasó ese halo noble y elitista que le ha sido siempre casi privativo y llegó a un ámbito social más numeroso.

El valor de la prensa como fuente para la historia es indudable; su estudio es de gran ayuda para conocer el pasado como objeto histórico y también como fuente de conocimiento de numerosos temas sociales, económicos y culturales, pues el periódico refleja la historia inmediata y, sobre todo, posee la capacidad de informar y formar opiniones (Saiz, 1996: 132). Sin negar que la gastronomía es ciencia, arte y comer regaladamente, es de suponer que debió existir una preocupación por conocer, practicar y extender dicho arte a una clase social más modesta, pero también más amplia, como comenzaba a serlo la incipiente burguesía española. Y todo ello sin olvidar que el XIX en nuestro país fue un siglo complejo, en el que las crisis y hambrunas se dejaron sentir en demasiadas ocasiones.

Esta investigación ha buscado reconstruir parte de esa historia casi desconocida a través de la prensa de la época, donde noticias, reportajes, folletines y artículos son retratos inestimables de nuestra memoria gastronómica; su visión desde el periódico es múltiple, poliédrica y, por tanto, más rica.

\subsection{Fuentes y metodología}

Debido a la importancia que la alimentación y la gastronomía tienen en la sociedad, así como a la ingente producción editorial referida, y debido a la escasez de investigaciones sobre este tema en la prensa española del siglo XIX, nuestro objetivo se ha centrado en verificar su presencia, clasificar su contenido y componer una parte de su historia en España a través de los periódicos de la época.

Se ha elegido este siglo por un doble motivo. Para el periodismo es el siglo por excelencia como vehículo de opinión, de cruzada política y de cultura, ante todo, y de aviso e información comercial, después (Seoane, 1992: 11). Para la gastronomía, porque fue cuando comenzó el conocimiento de las raíces culturales del mundo de la alimentación (Simón, 2003: 10). 
La parte cuantitativa de la investigación la hemos resuelto a través de datos obtenidos de tres clases de fuentes distintas: bibliografía contemporánea, bibliografía de la época y fuentes hemerográficas. Las dos últimas han sido analizadas a través de las colecciones digitalizadas del portal con acceso libre a sus fondos de la Biblioteca Nacional de España.

Se ha desarrollado una herramienta metodológica ad hoc, ya que la investigación no cuenta con precedentes que nos hayan podido guiar. La muestra de estudio se ha obtenido aplicando el análisis del discurso al conjunto de la prensa del siglo XIX del catálogo online de la Biblioteca Nacional a través de las palabras clave gastronomía y culinario(a). En total, se han recuperado 3.020 resultados, de los que 2.369 corresponden al término culinario(a) y 651 , a gastronomía.

Tras descartar aquellos utilizados en sentido figurado (sobre todo en referencia a asuntos políticos), se ha agrupado el contenido de los del ámbito gastronómico en cinco apartados: historia de la gastronomía, teoría gastronómica, publicidad, recetas y curiosidades. Grosso modo, esta clasificación se ha inspirado en los estudios bibliográficos de Simón Palmer (1997: 129-131), quien agrupa todo lo concerniente a la alimentación en tres categorías -fondo bibliográfico, personalidades del mundo de la gastronomía y recetas populares- que, a su vez, se distribuyen en siete grupos: recetarios, el comportamiento en la mesa, sanidad, América, moral y religión, agricultura y economía-industria-comercio.

\section{A propósito de los términos gastronomía, culinario, coquinario}

A finales del siglo XIX es posible confirmar en España el interés sobre el asunto gastronómico; por una parte, numerosos tratados culinarios lo ratifican; por otra, abundantes referencias en la prensa. Es ahora cuando el vocablo gastronomía aparece en los repertorios lexicográficos de la Real Academia Española (RAE, desde ahora) y de notables filólogos y eruditos. El diccionario de Núñez de Taboada incluye por primera vez las voces gastronomía y gastrónomo; como neologismo, gastronomía es la "Ciencia ó tratado sobre el modo de comer regaladamente"; por su parte, gastrónomo es "El que gusta de comer regaladamente" (1825: 744-745).

Desde mediados de siglo, gastronomía irá mudando y renovándose. Para algunos será "El arte de preparar los regalos de la mesa" (Salvá, 1846: 548); para otros, la "Ciencia de la sana é inteligente apreciación de los buenos manjares" (Domínguez, 1853: 849). La RAE alternará su definición, pero será siempre arte y afición; arte de preparar una buena mesa, una buena comida, de comer bien y afición a comer regaladamente, esto es, deliciosamente.

Gastronomía marcará en el XIX la clara diferencia entre comer para alimentarse y comer para gozar, siguiendo en este último caso los principios franceses iniciados el siglo anterior. Se trataba de seguir el patrón de la que era la gastronomía más atrayente y comprometida, cuyos tratados, recetarios y revistas especializadas se editaron profusamente en estos años ${ }^{1}$; el bibliógrafo francés Vicaire publicó en 1890 una ingente

${ }^{1}$ Puede consultarse en la Biblioteca Nacional de Francia: http://gallica.bnf.fr/?lang=ES. 
Bibliographie gastronomique: la cuisine, la table, l'office, les aliments, les vins, les cuisiniers et les cuisinières, les gourmands et les gastronomes, l'economie domestique... depuis le XVe siècle jusqu'à nos tours, consistente en la recensión de 2.500 obras de contenido culinario.

También nuestro país se interesaba por este asunto placentero. Insólitos términos derivados de gastronomía recoge Domínguez en su diccionario (1853: 849); gastrología y gastrolégico tendrán que ver con tratados de cocina y con "el arte de preparar manjares finos y delicados"; gastromanía con la "pasión por la comida, por los manjares suculentos y sabrosos", mientras que gastromaníaco será aquel "afectado de gastronomía". Todos tuvieron una vida corta y tan solo los dos últimos llegaron a 1918 para, después, desaparecer.

El vocablo más cercano en el uso a gastronomía fue el adjetivo culinario: "lo concerniente a la cocina" (Domínguez, 1853: 504), aunque hubo de esperar a 1970 para ser además sustantivo con la acepción "Arte de guisar" (RAE, 1970: 396).

La voz más antigua relacionada con lo gastronómico fue coquinario; como adjetivo, "lo que pertenece á la cocina"; como sustantivo equivalía a cocinero, siendo coquinarius regius (coquinario real) el "Oficio de dignidad en los antiguos palacios de nuestros Reyes, que cuidaba de lo que habia de comer la persona real" (RAE, 1780: 275). Esta voz latina remite a De re coquinaria (siglos IV o V), único recetario romano preservado, en el que Apicius, su autor, plasmó sus costumbres alimentarias (Martínez Llopis, 1981: 59). Desde su origen, coquinario mantuvo invariable el significado, ofreciendo además un uso bastante parco y siendo claramente superado por culinario, quizá por la fonética más sencilla del último.

Al margen de estas definiciones, no se encuentran otras sobre la voz gastronomía; por el contrario, en Francia sí lo precisó pronto Brillat Savarin en Fisiología del gusto ${ }^{2}$, el tratado gastronómico más relevante del momento:

"Entiéndese por gastronomía el conocimiento razonado de cuanto al hombre se refiere en todo lo que respecta á la alimentación. Tiene por objeto velar por la conservación del hombre, empleando los mejores alimentos. Esto lo consigue dirigiendo con principios fijos, á los que buscan, suministran ó preparan cosas capaces de convertirse en alimentos". (Brillat Savarin, 1869: 58)

Es interesante observar cuándo aparecen estas voces en la prensa y cuándo son admitidos en los diccionarios académicos. Coquinario se normaliza en 1780, pero no lo encontramos en prensa hasta 1849; gastronomía y culinario se verifican antes en la prensa que en los diccionarios: gastronomía en 1817, siendo aceptado por la RAE en 1852 , y culinario en 1834, mientras la RAE no lo admitió hasta 1884. Esto es, siguen procesos distintos. El fenómeno habitual es el segundo, confirmando que los diccionarios son repertorios sancionados por el uso de la colectividad y, por lo tanto, las palabras solo llegan a ellos cuando abandonan su uso pasajero para hacerse general (Alvar, 1992: web). Según esto, habría que entender que a lo largo del siglo XIX el

2 Se ha seguido la traducción del conde de Rodalquilar (1869). 
gusto por la cocina (en su sentido más lúdico) se fue generalizando, al menos entre las privilegiadas clases sociales que, además de alimentarse, disfrutaban con ello.

Respecto a coquinario, su precoz entrada en el diccionario no se ve corroborada en la prensa; antes bien, su primer registro tarda más de sesenta años, hallándose en el relato "Sueño de un glotón" en La Ilustración de Madrid (30-6-1849).

El vocablo gastronomía figura por primera vez en prensa a propósito de una despectiva reflexión sobre el sentido que debe darse a la Ilustración y su aplicación en diferentes países; en este caso, la Ilustración francesa era definida despreciativamente como "el arte de dar sabor á la existencia física y de adornar la vida social [y a los franceses habría que dejar] su gastronomía y erudición á la violeta" (Crónica científica y literaria, 8-4-1817: 3).Con el significado actual, anunciando La gastronomía, ó los placeres de la mesa, en La Abeja del Turia (4-8-1820: 4). Se trata de la traducción del popular poema La gastronomie de Berchoux (1810), profusamente divulgado durante meses en el Diario de Madrid, Mercurio de España, Nuevo diario de Madrid, entre otros periódicos.

La primera referencia a culinario se descubre en La Revista española (4-2-1834) en relación a un equívoco sobre qué artista culinario -confitero a la sazón- elaboró los dulces para el baile de Abrantes. En general, se usa completando a sustantivos del campo semántico de arte y, en sentido figurado, en comparaciones del ámbito político.

Otras voces como gastrolégico no llegaron a la prensa, o apenas subsistieron unos años después de haber sido desterradas de los diccionarios; en este último caso, está gastromanía, placer al que se consagran Luis XVI, monarca irresoluto y marido cómodo (La Voz, 9-1-1835: 1), y el parodiado vecino de El Moro Muza por su desenfrenada afición a la comida (26-6-1863).

Y al contrario, la constancia y pervivencia de las expresiones gastronomía, culinario y coquinario en la prensa decimonónica puede servir para ratificar lo que ya han hecho los estudios bibliográficos con la catalogación de más de dos mil obras hasta el 1900, y es que la alimentación en su vertiente regalada, hedonista y artística fue alcanzado relevancia en nuestro país a lo largo del siglo XIX.

\section{El discurso gastronómico en la prensa del siglo XIX}

Lo más notorio del tema analizado fue el cruce epistolar publicado por La Ilustración española y americana del Dr. Thebussem y Un cocinero de S.M. entre 1876 y 1877. El primero fue el pseudónimo con el que Pardo de Figueroa firmó sus escritos; el segundo corresponde a Castro y Serrano, periodista y buen conocedor de la gastronomía como Thebussem.

El intercambio de cartas se aproximaría a un tratado del estado de la gastronomía en España. Atesora conceptos actuales, recomendaciones y reflexiones culinarias que fueron seguidas con interés por numerosos lectores y, lo que es más importante, fueron llevadas a la práctica en diversas ocasiones. Su trascendencia tuvo como resultado la publicación en 1887 de La mesa moderna, que reprodujo las cartas y que se completó con un apéndice de tres cartas inéditas también relacionadas con el arte culinaria.

Su contribución al conocimiento de la gastronomía ha sido considerado "el intento más serio de sentar las bases de una cocina nacional” (Bueno; Ortega, 1998: 3). Los 
contenidos fueron variados, entre ellos destacan el idioma y la redacción de los menús de la Casa $\mathrm{Real}^{3}$, el reconocimiento a los jefes de cocina, la carencia de buenos recetarios, la crítica a la imitación de la cocina francesa, la necesidad de una cocina nacional y el olvido de la prensa para con la gastronomía.

Sobre el idioma en que debían redactarse los menús, Thebussem exhorta a usar el castellano y no el francés, como era habitual; sobre su redacción, insta a que estén exentos de faltas de ortografía, a que reúnan cierta belleza artística y tipográfica y a que se rubriquen con el nombre del jefe de cocina como distinción a su labor (8-41876: 242-243).

Respecto a los recetarios, si bien no son tan numerosos como los franceses, tampoco parece cierto que sean tan escasos y pobres como sostienen los autores. Recientes estudios verifican abundantes ediciones en el siglo XIX, sobre todo a partir de la segunda mitad, cuando se concentran más del cincuenta por cien de las publicaciones (Simón, 2003). Los temas fueron heterogéneos: agendas y almanaques culinarios para el ama de casa, tratados de cocina económica, sencillos manuales de cocina, obras de repostería, licorería, helados y sorbetes, libros para órdenes religiosas, cocina de cuaresma, diccionarios domésticos con recetas de fácil ejecución, excelentes tratados de prestigiosos gastrónomos -Muro, López y Camuñas, Doménech, Praussols-, reediciones de obras antiguas como la de Altamiras y traducciones casi siempre del francés.

La crítica a la pretendida imitación de la cocina francesa discurre paralela al debate sobre la existencia, o no, de una cocina nacional. Es Un cocinero de S.M. quien advierte de las consecuencias derivadas de emular en exceso la cocina gala, siendo la más grave el detrimento de nuestra mesa nacional (La Ilustración española y americana, 30-7-1877: 7). Debaten los autores acerca de la conveniencia de procurar la unidad gastronómica nacional que, reconocen, no existe, pues tenemos federada la cocina; por ello, y porque en todas las comarcas españolas hay especialidades dignas de figurar en las mesas de palacio, la forma de lograr una cocina nacional es pedir a cada región su receta y formar así un repertorio de "manjares ilustres españoles" (15-12-1877) y "una colección ó mosaico de alimentos heterogéneos" (30-1-1878).

El olvido de la gastronomía en la prensa que censuraba Thebussem no se corresponde del todo con la realidad. Sí fue innegable que La Ilustración española y americana "rompió la marcha" porque abordó temas críticos y trascendentales sobre nuestra gastronomía; sin embargo, no lo fue que solo a partir de finales de la década de 1870 algunos periódicos se ocuparan de reproducir listas de banquetes y de otros asuntos. Como veremos después, ya desde principios del siglo XIX se constatan abundantes referencias en la prensa.

La aportación de estos dos eruditos al saber culinario fue retomada años más tarde por Dionisio Pérez. Su Guía del buen comer español (1929) buscó recuperar la postrada gastronomía española, reconociéndole a sus predecesores el haber sacado "a la cocina española del olvido y postergación en que había caído, [...] señalar los hurtos que en

${ }^{3}$ En La Época también se publicaron algunas de estas cartas: Jigote de lengua apareció el 18-4-1876 en la primera plana; la segunda -respuesta de Un cocinero de S.M.-, el 19-4-1876, también en la portada. 
ella habían hecho otras cocinas extranjeras y ponerla en estimación de los propios españoles" (1929: 9-10). Idéntica intención hallamos casi cincuenta años después, cuando Luján y Perucho proyectaron continuar la tarea de Dionisio Pérez (1972: 52).

La tríada compuesta por Thebussem y Un cocinero de S.M. primero, por Dionisio Pérez, después y por Luján y Perucho por último, resalta la indiferencia cíclica que padecía la gastronomía española. Según ellos, el interés decayó en varias ocasiones -finales del siglo XIX, 1929 y 1972-; desde las producción editorial, ya señalamos antes su importancia; desde la prensa, hay testimonios de que la gastronomía fue un tema que interesó a la sociedad del momento y, aunque incomparable a la importante culinaria francesa, tampoco es cierto que fuera irrelevante y nula como se ha afirmado habitualmente. Así se desprende de los resultados recuperados del catálogo online de la Biblioteca Nacional concernientes a la prensa decimonónica y que, a continuación, se muestran agrupados en cinco apartados: historia de la gastronomía, teoría gastronómica, publicidad, recetas y curiosidades.

\subsection{Historia de la gastronomía}

Las noticias históricas son abundantes. Se trata en general de relatos que recorren la Antigüedad hasta llegar a los tiempos modernos con referencias a Italia, Francia, Inglaterra, Alemania y España.

Un extenso retrato en el remoto Egipto nos ofrece El Clamor público (7-4-1847: 3-4), extraído de las obras de los egiptólogos Wilkinson y Rossellini4. Bajo el titular "Cocina egipcia" del 800 a. C. se ofrecen datos provenientes de láminas y dibujos del Museo Británico de Londres, donde se observan cocinas, cocineros y delicadas viandas. Eran empleados en estos trabajos esclavos para servir la mesa y enanos y personas deformes para los trabajos más viles. Otro retrato más crítico censura la prohibición de usar cebollas y puerros en sus guisos y califica el mal gusto de sus gobernantes que usaban para comer cosas destinadas al goce de otros sentidos como "el estrambótico brevage de Cleopatra sazonado con perlas desleídas", según el Eco literario de Europa (1851: 468-504) que, asimismo supone rudeza y rapacidad para los reyes bárbaros y describe los magníficos y delicados banquetes árabes. De la gastronomía británica dice que es gran deudora de la romana. Hay también una extensa descripción de la cocina renacentista española, extraída de notas de Isabel la Católica; para terminar, eso sí, con la cocina francesa.

Las referencias a la antigua Roma ponen de manifiesto su importancia y destrezas en la labranza y variedad de productos para las clases más humildes y abundantes platos para los patricios, cuya comida consistía en una primera entrada de cosas ligeras -huevos y ostras-, seguida del "grueso de batalla" -carnes especiadas-, para terminar con los postres. Con el tiempo, los romanos fueron ganando en delicadeza, pero también en "una magnificencia tan estremada que fue necesario hacer leyes para poner límites a los banquetes" (El Instructor, 7-1837: 7-9). En su historia gastronómica repararon incluso revistas científicas y literarias de alta calidad intelectual como la

4 Accesible en https://archive.org/details/modernegyptthebe02wilk y https://archive.org/details/imonumentidelle05rosegoog 
Revista de España que en el número 28 de 1872 ofrece una larga estampa de más de treinta páginas.

Igualmente, hallamos opiniones contrarias a las costumbres romanas, cuya gastronomía pronto convirtieron en una extremada licencia y corrupción; sus cocineros, gente importante, "[eran buscados] con avidez, se les dispensaban las mayores consideraciones, y se les pagaba en proporción á su mérito. / Había en Roma un cocinero á quien le daban cuatro talentos anualmente, que equivalen á unos 76,000 rs. vn. Marco Antonio quedó tan satisfecho de uno de sus cocineros en el convite que dió á la reina Cleopatra, que le agració con una ciudad por recompensa" (La Iberia, 7-3-1857: 3).

En los recorridos históricos, hay lugar también para la historia gastronómica española que, en general, recibe críticas negativas: se afirma que estábamos muy atrasados, que nuestras fondas (incluso las más reputadas: Cotte, de Lhardy, Prosper, Cisne, Perona) no son en nada comparables a la media francesa, y nuestra cultura e interés gastronómico se centra muchas veces en noticias de espectáculos bárbaros y anecdóticos como el catalán que se zampó media vaca o el asturiano que se embuchó un pienso de cebada en Aranjuez, es decir, no se comprende el verdadero significado de la palabra gastronomía (La Iberia, 7-3-1857: 3).

\subsection{Teoría gastronómica}

Aunque dispersas, se encuentran también reflexiones sobre el arte culinario, su vigencia y consideración moral, sus funciones, sobre el uso de tecnicismos y extranjerismos, sobre los condimentos y costumbres.

Una cuestión interesante es el objeto y la utilidad del arte culinario. Para unos debía consistir en hacer los alimentos gratos al paladar y de fácil digestión; sin embargo, se quejaban de que las personas de gran refinamiento buscaban con frecuencia "excitar el paladar, estimular un apetito lánguido ó lisonjear la vanidad" (El Instructor, 1/1841: 30 ). Es por eso por lo que la gastronomía deja de ser un arte útil para volverse una calamidad que provoca muchas enfermedades e, incluso, la muerte.

Como un arte perdido lo describen algunos, sobre todo al compararlo con las comidas pantagruélicas de los antiguos, donde egipcios y romanos son modelos culinarios ejemplares, capaces de comer hasta la extenuación pero, eso sí, con refinado y original gusto: rodaballos, lenguas de papagayo, pavos reales, tordos, cisnes, erizos... componen exóticos menús en sus banquetes (La Ilustración de Madrid, 4-8-1849: 7).

A favor y contra la gastronomía no faltan artículos. Ciertos juicios negativos sostienen que la gastronomía progresa de modo tan vergonzoso como sorprendente ( $E l$ Observador, 16-8-1852). Los elogios a los banquetes descomunales son un denominador común. Abundan las descripciones de sus platos, el número de invitados y el tiempo invertido en ello; cuanto más comensales y mayor número de platos, más favorable es la semblanza del banquete. Quien mejor comía equivalía muchas veces a quien más comía; no son de extrañar, pues, los fallecimientos por apoplejía a una edad temprana. Quizá por esta cuestión de salud e igualmente por una moralina pacata son abundantes los textos que asimilan gastronomía a gula. El hedonismo, no lo olvidemos, era condenado desde altares y tribunas sociales. Y la gastronomía, tampoco lo olvidemos, era comer regaladamente. Disfrutar una buena comida era, y es, un placer. 
Desde siglos, la gula ha sido uno de los siete pecados capitales para la moral cristiana $\mathrm{y}$, al parecer, se consideraba así el apetito desordenado, el exceso al comer y beber, aunque también el hecho de disfrutar. En algunas columnas de la prensa decimonónica no se distingue entre la glotonería y la gastronomía, formando los dos un totum revolutum indebido e inexacto:

"La gastronomía ó mejor dicho la glotoneria es el placer de las personas de espíritu corrompido, y la pasion de los necios cuando llegan á la edad madura, que sirve tan solo para estimular el espíritu de los primeros y embrutecer el de los segundos". (El Clamor público, 3-8-1856: 3)

Por su parte, El Monitor de primera enseñanza tilda la gula de vicio de nauseabunda naturaleza, reprobando el haber sido elevada a la categoría de ciencia y a la que tachan de "especioso título de gastronomía" (16-7-1864). No dudan algunos en atribuir a la satánica serpiente del paraíso terrenal la responsabilidad del seductor pecado de la gula (El Globo ilustrado, 1-6-1867: 1).

Pero igualmente se describían bondades, como es su predisposición al ánimo y a las relaciones sociales para hermanar a los hombres políticamente incompatibles ( $E l$ Clamor público, 18-12-1851: 3). Se llega a considerar como el signo de la civilización de un pueblo. ¿Las razones?: la perfección de los alimentos, entendiendo por esta los platos variados y bien condimentados, resultado de una sociedad adelantada ya que promueve el comercio y la industria, pero también ayuda en la conquista amorosa y en el fortalecimiento del vínculo matrimonial. (Museo mexicano, 1845: 60-64).

De ahí, que no sean extrañas afirmaciones como las del que el siglo XIX es un siglo esencialmente gastrónomo en el que se vive para comer, aspirando todas las clases sociales a tener una mesa suculenta; un siglo en que todo se compone comiendo y para ello se buscan motivos innumerables como cumpleaños, Carnestolendas, y grandes festividades religiosas (La Época, 9-2-1855: 4). Retratos costumbristas de romerías describen establecimientos, comidas y productos típicos para la festividad. En la romería de San Isidro en Madrid, abundaban los puestos de bollos y de buñuelos, las tiendas surtidas de bizcochos, roscones de pan duro..., y las fondas entapizadas que "ostentaban sobre sus entradas los nombres mas caros á la gastronomía madrileña", brindando en su interior apetitosas salsas, sólidos suculentos, cantarillos de leche de las Navas, roscones y nobles jamones (Cartas españolas, 6-1832: 184).

No faltan tampoco los debates lingüísticos. Uno de las más curiosos aparece en $E l$ Imparcial (3-5-1867: 3-4), donde se afirma que el siglo XIX será inmortalizado por el ferrocarril, la telegrafía eléctrica y también por haber impulsado el renacimiento de la ciencia gastronómica. La gastronomía ha enriquecido los idiomas con sus vocablos nuevos. Reflexiona Velisla (pseudónimo de Manuel Silvela en sus colaboraciones periodísticas) sobre estos neologismos gastronómicos y la Real Academia de la Lengua que, en su opinión, mantiene una verdadera nomenclatura feudal. La ignorancia gastronómica de la Academia se revela por la ausencia de todos los manjares nuevos en el diccionario, así como por las extrañas definiciones de los platos más antiguos y vulgares como, por ejemplo, la tortilla que de seguir la definición del diccionario, terminaría siendo una mayonesa frita. Interminables, continúa Velisla, parecen ser los bodrios académicos: gualatina, panetela, jusello, alboronias, sopaipa, pipiripao y un sinfín de vo- 
cablos gastronómicos para los que urge una reforma académica urgente; y para ello propone admitir en la Academia a un gran cocinero o bien obligar a los académicos a estudiar los tecnicismos gastronómicos. Poco o nada debieron considerar desde la Academia, pues ni accedieron a que un cocinero formara parte de ella, ni suprimieron las voces criticadas que, hay que decirlo, siguen vigentes en el diccionario actual.

Se procura también prevenir sobre ciertos hábitos como el de comer helados por la noche, tal y como leemos en el folletín de El Contemporáneo (18-3-1865:1), que se justifica porque afligen las vías digestivas; si hacemos caso del texto, parece ser que los helados solo eran admisibles como "transición entre los platos calientes y los vinos espirituosos de los postres".

Otra práctica que se censura, y se recomienda subsanar, es la carencia de menús en las fondas: "siempre saca el mozo lo que al amo de la fonda le place, puesto que el que come no puede pedir porque no sabe lo que hay en la cocina" (El Clamor público, 149-1850: 3). El autor de este breve recomienda introducir el menú tal y como existía en otros países; novedad que redundaría en los consumidores pues, además de poder comer aquello que más les apeteciera, sabrían de antemano el precio de los platos. Esta mejora, prosigue el autor, implicaría una auténtica publicidad para las fondas del país.

Un retrato nada favorable de las cocinas de las fondas y los obradores de reposterías y confiterías permite conocer su insuficiente higiene (El Clamor público, 22-101850: 3). Se freía y asaba toda clase de alimentos "á puerta de calle", provocando densas nubes de humo que sofocaban y hacían "mal contraste al lado de lujosas tiendas". En cuanto a las reposterías, los manjares estaban al descubierto "sitiados por enjambres de insectos repugnantes, que aspirando los jugos los dejan exaustos de la parte alimenticia". Se aconseja corregir esta nociva costumbre con escaparates o redes metálicas de mallas como las que utiliza Lhardy en su prestigiosa confitería.

\subsection{Publicidad}

Los anuncios se refieren sobre todo a cocineros, alimentos, fondas y establecimientos de alimentación. Son tipográficos, sin ilustraciones e informativos, como corresponde a esta publicidad primeriza; sin embargo, la presencia de elementales recursos persuasivos -el adjetivo, sobre todo el superlativo- va progresivamente extendiéndose. La mayoría carecen de sus marcas formales y distintivas para aproximarse a lo que Castaños (2007: 341) denomina "publicidad disfrazada".

Los cocineros brindan sus servicios en escuetos avisos. En el Diario de Madrid, se anuncia Raucurel, "cocinero, que guisa bien y prontamente" (17-9-1809: 3). Habitualmente se ofrecían para trabajar en casas particulares y para impartir "lecciones en el arte culinario" (El Heraldo, 2-12-1849: 4). Aunque más inusuales, se han encontrado anuncios de cocineras que decían ser artistas en gastronomía: "Una señorita francesa, perfectamente instruida en dicho arte, desea colocarse de cocinera en alguna casa importante, por lo que daran excelentes informes" (Diario oficial de avisos de Madrid, 6-3-1866: 3).

La publicidad de fondas era frecuente en los periódicos. Los asuntos son variados; desde el precio de los cubiertos -como el de la fonda pastelería de Servie-Lardy a 20 reales (El Español, 19-12-1846: 4)- hasta inauguraciones como la de la Fonda Espa- 
ñola, donde podía encontrarse desde "el bodegón español hasta la más refinada mesa parisiense", con gran una gran versatilidad al servir con esmero platos franceses -cotelet á la papillot- y españoles -chuletas de ternera- (El Clamor público, 5-9-1847: 3 ). Algunas fondas utilizaron como ventaja competitiva tener un reputado cocinero; en la madrileña Fonda de Barcelona, estaba a cargo Seselli, "uno de los mas acreditados del arte culinario" (El Clamor público, 25-8-1850: 4).

Otros anuncios nos ayudan a conocer cómo eran y qué servicios ofrecían los establecimientos más acreditados. Así, la nueva fonda en la carrera de San Jerónimo, dirigida por Mr. Prosper innova con un buen servicio, lujo, comodidad y variedad de platos; allí, las familias pueden reunirse "en habitaciones sotto voce y las comidas están al alcance de todos los bolsillos" (La España, 25-9-1850: 4).

Uno de los más afamados de Madrid, y también uno de los que más noticias generó en la prensa fue el de Lhardy, inaugurado en 1839 y vigente en la actualidad. Su propietario Emilio Huguenin transformó el nombre del parisino Café Hardy en Lhardy, y lo convirtió en su propio apellido (Altabella, 1978). Se localizaba en la Carrera de San Jerónimo, que al parecer se había convertido en un escaparate gastronómico por los muchos establecimientos que se abrieron allí; la casa de Prosper, las fondas de Petrona, Iberia, Dos Amigos, Caballo blanco y Leones atraían "gran número de tragones que ponen en movimiento sus incansables mandíbulas" (El Clamor público, 5-10-1852: 3). Aunque, sin duda, fue el de Lhardy el que congregó a más personajes famosos; banqueros, políticos, médicos, profesores, escritores... no faltaron en sus salones románticos:

"El restaurant y repostería de Lhardy es el Senado de los gastrónomos: su cocina es seria y clásica; sus salsas son indiscutibles, y no han estado nunca al alcance de todas las fortunas. [...] El público conocía sus pastelillos, embutidos y los manjares de repostería que se expenden en la tienda del piso bajo; los hambrientos contemplaban en éxtasis las cabezas de jabalí que suelen exponerse en el escaparate, y diríase de ellos que estaban dispuestos á luchar contra las fieras; la casa, á pesar de tener cuarenta y siete años de antigüedad, parecía siempre de reciente fundación". (La Ilustración española y americana, 15-11-1886: 2).

Los anuncios de alimentos también están presentes en la prensa decimonónica. La publicidad estacional se observa en determinadas fechas como la Navidad, con la proliferación de anuncios de productos típicos: nunca falta el mazapán de Toledo; dulces exquisitos como "limoncillos, naranjillos y nuez elaborados por los monjes de Redondela"; para los aficionados al dulce se ofrece un gran surtido de almíbares de melocotón, guinda, tallos de limón, flor de borraja, nuez, pimiento, membrillo y sandía (Diario oficial de los avisos de Madrid, 6-12-1849). Llaman la atención los titulares de estos anuncios -“Aviso a las personas de buen gusto", "Para los aficionados al dulce"-, que dejan de ser meras frases informativas para apelar persuasivamente a sus potenciales públicos, conteniendo el beneficio básico del producto y cumpliendo con su función de atraer, seducir e incitar al lector; son incipientes titulares selectivos, cuyo segmento de población son personas exquisitas y golosas.

La publicidad de almacenes, fábricas y tiendas de ultramarinos, aunque en menor número que la anterior, también destaca; La Begoñesa se anuncia como fábrica de con- 
servas alimenticias "con preferencia á la preparación de los delicados pescados de la costa cantábrica como son sardinas, merluza, atún, congrio, angulas, besugo y calamares, etc." (La Esperanza, 22-1-1858: 4). Igualmente, los colmados dan a conocer sus suculentos manjares que, como en El Colmado Madrileño, recuerdan -salvando las distancias- las actuales tiendas gourmet: pichones dorados al fuego, percebes, langostinos, ostras y, por supuesto, gran variedad de vinos (El Lloyd español, 25-2-1864: 2).

\subsection{Recetas}

A lo largo del siglo XIX, los recetarios llegaron al mercado español generalmente de dos formas: libros relevantes del arte gastronómico francés -traducidos u originalesy los de autores españoles. Entre los primeros, las obras de Brillat Savarin, Carême y Gouffé. Entre los españoles, abundan recetarios sin reflexiones culinarias, donde la publicación de La mesa moderna del Dr. Thebussem y Un cocinero de S.M. fue una excepción, lo que ha llevado a algunos estudiosos a afirmar que este siglo ofrece un panorama de obras de cocina mediocres y de vulgaridad adocenada que en su mayoría han sido copiadas o traducidas del francés (Martínez Llopis, 1981: 358).

En España, la prensa divulgó recetas sobre todo en revistas para la mujer ( $E l$ Hogar) y, excepcionalmente, en semanarios de carácter lúdico como La Risa que decía ser, entre otras obras, de gastronomía. Desde su primer número incluyó la sección titulada "Ambigú" con diversos propósitos: educar en la mesa, enseñar a ser un económico y buen cocinero, repostero, pastelero y botillero, y dar noticia de "cuanto han escrito de gastronomía los sabios de todas las naciones, sin olvidar los famosos guisos provinciales de España (La Risa, 2-4-1843: 12).

A pesar de su corta vida, apenas año y medio, recogió entre sus páginas ingeniosos retratos de la mala educación en la mesa, reglas y consejos útiles que se han de observar, recomendaciones sobre el arte de trinchar y servir y numerosas recetas bajo el epígrafe "Manual del cocinero y cocinera" que comenzó en el tercer número (23-41843) y se mantuvo hasta el final (8-9-1844). Lamentablemente, no hubo ocasión para los escritos de los sabios gastrónomos de todas las naciones, como anunció en su primer número. Estos textos fueron extraídos del Manual del cocinero, cocinera y repostero, con un tratado de confiteria y botillería, y un método para trinchar y servir toda clase de viandas, y la cortesania y urbanidad que se debe usar en la mesa que en 1828 tradujo del francés Mariano de Rementería y Fica. El del retrato de la mala educación pudo servir, quizá, de inspiración a Larra para El castellano viejo, publicado en 1832 en El pobrecito hablador.

El Hogar (1866-1867), órgano de la agencia de servicio del mismo nombre, contenía una sección de interés gastronómico -arte de trinchar y arte culinario- con indicaciones de comidas que usa la clase media y que se componen de dos sopas - un plato volante y otro fuerte- y su postre de repostería, pudiendo consistir el otro de frutas de la estación y advirtiendo que elegirán platos de fácil ejecución, esto es, sencillas recetas autóctonas muy alejadas de las casi imposibles recetas francesas y, por ende, de las mesas de aristócratas y burgueses enriquecidos: puré de patatas, croquetas de ave, tostas de pan con manteca, conejo frito, rosquillas de Fuenlabrada, jamón, salsa de anchoas... 
Lo más destacado, sin embargo, fueron las numerosas recetas que a partir de la década de 1880, publican semanarios y almanaques. Se constatan en el Almanaque Bailly-Bailliere (1897), La Ilustración española y americana (1899), Nuevo Mundo (1899) e incluso algunos como El Universo ilustrado difunde en todos los números entre 1886 y 1887 breves recetas en una sección llamada "Gastronomía".

\subsection{Curiosidades}

En este grupo se han incluido noticias de contenido diverso; algunas sobre productos de carácter insólito, como la columna que el Semanario pintoresco español dedica los nidos del Tonquin, bocado regaladísimo en las grandes mesas y cuya recolección se realiza dos veces al año, siendo los más apreciados "los de las cavernas más húmedas y que los pájaros no han ensuciado todavía con la nidada: son mas blancos, limpios y trasparentes que los demás. [...] Los chinos dicen que no hay cosa mas estomacal, estimulante y sana que este alimento; pero su único mérito consiste en el preció á que se venden, porque lisongea á la vanidad de los ricos que los consumen" (3-8-1840: 7).

El Museo de familias publicó en 1839 (128-145) un extenso reportaje sobre los usos y costumbres en China: carácter, educación, atuendo, juegos, ceremonial y gastronomía, entre otras. Allí leemos que unas aves parecidas a las golondrinas hacían sus nidos en las costas de Tonquin, Java y Cochinchina con pececillos y espuma de mar; una vez que los abandonan, se recogían y vendían. Los nidos "se asemejan en figura y tamaño á la corteza de un grueso limón adobado, y tienen la propiedad de dar á los guisados en que se mezclan un gusto harto esquisito" (138).

Sobre las ostras, producto extraño en las mesas de entonces, encontramos una exégesis del tratado Ensayo sobre las ostras de 1818 del médico francés Pasquier, previniendo sobre los inconvenientes de la gula y avisando del desagradable rato de una mala digestión (Crónica científica y literaria, 11-1-1820: 4); sin embargo, estas reticencias se superaron y el molusco pasó a ser un bocado sabroso y excitante (El Mundo ilustrado, 1880, $\mathrm{n}^{\circ} 41$ : 11).

De las patatas sabemos que eran a mediados del siglo XIX un artículo de lujo y no el producto indispensable y de gran consumo en nuestra dieta de hoy; este tubérculo que antiguamente nadie comía en España, porque era el alimento de los cerdos, y que después se ha considerado cosa despreciable y de poco valor, ha venido á ser un ramo de lujo culinario: "Si Dios no lo remedía, ha de llegar el caso de que al convidar á comer una persona rica á otra amiga suya, la diga, como cosa rara: «Tendremos un platito de patatas fritas»" (El Espectador, 16-6-1847: 4).

Otro producto valorado de forma muy distinta a la actual es el azafrán. Lo hallamos en un folletín de El Heraldo, donde se reprende con dureza el uso que las cocineras hacían, ya que "pone las salsas bonitas". Tal condimento, leemos, lo omiten en sus tratados Marie-Antoine Carême y Brillat-Savarin, referentes del arte culinario del momento; sin embargo, en nuestro país, y en concreto en los campos de Murcia, le augura el autor un largo porvenir (13-4-1850: 2).

El Genio de la libertad (21-1-1856: 3) reproduce una noticia aparecida en Le Siècle francés sobre la carne de caballo servida en varias escuelas de veterinaria. La reforma de las costumbres gastronómicas en el país, dice el autor, propiciaría todo el carácter de 
un beneficio nacional de aprovecharse para el consumo los 30 millones de kilogramos de carne que se calcula provienen del millón de caballos que perecen anualmente.

Tampoco faltan referencias chocantes como la denominada Sociedad del hambre que se reunía a menudo en una fonda barcelonesa "para saciar su devorante apetito". La integraba gente divertida, de carreras ilustradas, cuya inclinación favorita era la gastronomía (La España, 27-4-1850: 2).

Los decesos ocupan también lugar en el ámbito gastronómico; sobre todo, con atributos y elogio de personajes cuya celebridad provenía de su afición, saber o dedicación al arte culinaria. Como Mr. Very, vividor, juerguista, disfrutador e hijo de un célebre fondista parisino (El Clamor público, 1-12-1846: 4). O la muerte por apoplejía fulminante de Chevet, famoso mercader de comestibles del Palais-Royal en París. La causa en ambos casos se atribuyó a sus excesos culinarios, falleciendo el primero al levantarse de la mesa (La España, 1-3-1857).

Son frecuentes, asimismo, narraciones culinarias excéntricas como la de un glotón irredento -Heliogábalo moderno- que pretextaba organizar banquetes de doce cubiertos para después fingir que no asistía nadie y poder comérselo todo él. (La Época, 224-1865: 4).

No faltan, por último, extrañas y probablemente absurdas noticias sobre la culinaria regional como la que atribuye a la catalana tener entre sus platos predilectos "culebra en salpicón, lagarto en ajo blanco y rata socochada" (El Clamor público, 18-4-1849: 4). O quizá fuera una lamentable realidad que llevó a algún periódico de la época -El Genio de la libertad- a reprobar que el pueblo comía para vivir y el gobierno vivía para comer.

\section{Conclusiones}

Tras el análisis realizado, una primera evidencia parece clara: la gastronomía tuvo una presencia importante en la prensa española del siglo XIX. Como se vio al principio de este trabajo, los recientes estudios bibliográficos han puesto de relieve la abundante producción editorial, lo que se refrenda, a su vez, por el importante peso que la gastronomía adquirió en las revistas y diarios de la época con noticias y artículos que, según avanza la centuria, ocupan cada vez más espacio en sus páginas.

El célebre intercambio epistolar del Dr. Thebussem y Un cocinero de S.M. ${ }^{5}$, publicado entre 1876 y 1882, fue probablemente el testimonio más riguroso del asunto gastronómico en nuestro país. La investigación lo ha señalado siempre, coincidiendo con los autores en la totalidad de sus afirmaciones; sin embargo, y como hemos señalado, no se corresponden del todo con la realidad. Precisamente, nuestra investigación nos lleva a disentir respecto al aserto de que la prensa tenía olvidada a la gastronomía; al contrario, durante el siglo XIX, y sobre todo a partir de la década de

${ }^{5}$ Dr. Thebussem es el pseudónimo de Mariano Pardo de Figueroa, Medina Sidonia (Cádiz), 1828. Estudio Latín y Filosofía y Derecho en Sevilla, Granada y finalmente Madrid, donde obtuvo el grado de doctor en Jurisprudencia. Un cocinero de S.M es el pseudónimo de José de Castro y Serrano, Granada 1829, donde se licenció en Medicina. Se trasladó después a la Corte y alcanzó notoriedad como escritor. 
1850 , los periódicos fueron interesándose cada vez más por ella. En sus planas dieron cabida a innumerables noticias, reflexiones y críticas. Su diversidad y abundancia ha permitido proponer una original categorización formada por cinco grupos: historia de la gastronomía, teoría gastronómica, publicidad, recetarios y curiosidades.

El primero ofrece noticias tanto de la Antigüedad como de la culinaria contemporánea; en él, Roma ocupa un lugar temprano y destacado. Acerca de la teoría gastronómica, su heterogeneidad permite abordar contenidos variados, donde la semblanza de banquetes y la gula es una de las preocupaciones más sobresalientes. Junto a ellas, la función social de las comidas, los hábitos y prácticas censuradas -la inexistencia de menús en los establecimientos, la insuficiente higiene de confiterías y fondas-, permite componer un retrato costumbrista pero, sobre todo, de la realidad objetiva de la gastronomía en España.

A través de la publicidad se muestra un repertorio de productos y servicios que utilizaron esta técnica de comunicación comercial. Se han constatado escuetos avisos de cocineros, de fondas, alimentos, almacenes y tiendas de ultramarinos. Se ha de suponer, entonces, que existía una oferta y una demanda en este sector que diera sentido a la inversión publicitaria, pues esta, además de utilizarse para la introducción de nuevos productos, incrementa la demanda y acelera el consumo.

En cuanto a las recetas, el medio por excelencia para divulgarlas fueron los recetarios; sin embargo, podemos afirmar que, tras ellos, la prensa se convirtió en un soporte estimable; y no solo las privativas de la mujer, sino que populares semanarios satíricos como La Risa las publicaron desde sus inicios, e incluso otras prestigiosas revistas ilustradas -La Ilustración española y americana, El Universo ilustrado- ofrecieron a sus lectores numerosas recetas, sobre todo en las dos últimas décadas del siglo, cuando los asuntos gastronómicos ocupan más espacio en la prensa.

Por último, el grupo Curiosidades acapara noticias bien de productos insólitos en la época -las ostras, los nidos de Tonquin-, bien de noticias luctuosas de conocidos personajes, cuyos excesos en la mesa acabaron abruptamente.

Testimonios los referidos que, creemos, han de contribuir a un mayor conocimiento del panorama gastronómico en España, pero también a plantear una revisión de ciertas afirmaciones y teorías. Es necesario reivindicar y reconocer el papel de la prensa como fuente de conocimiento para la gastronomía: la constatación de abundantes noticias significa también la conveniencia de abrir líneas de investigación en este campo, lo que redundaría -confiamos- en sabrosas y nutridas aportaciones.

\section{Referencias bibliográficas}

ALTABELLA, José (1978): Lhardy. Panorama histórico de un restaurante romántico 1839-1978. Madrid, Imprenta Ideal.

ALVAR, Manuel (1992): "Los diccionarios académicos y el problema de los neologismos", en El neologismo necesario. Madrid, EFE, pp. 51-70: http://www.cervantesvirtual.com/obra-visor/los-diccionarios-acadmicos-y-el-problema-de-los-ne ologismos-0/html/01099ca2-82b2-11df-acc7-002185ce6064_6.html. [fecha de consulta: 7 de marzo de 2014]. 
BRILLAT SAVARIN, Jean Anthelme (1869): Fisiología del gusto ó meditaciones de gastronomía trascendental. Madrid, Librería Alfonso Durán.

BUENO, Pilar y ORTEGA, Raimundo (1998): "De la fonda nueva a la nueva cocina. La evolución del gusto culinario en España durante los siglos XIX y XX". Revista de libros de la Fundación Cajamadrid, no 19-29, pp. 1-17.

CASTAÑOS, Ángel J. (2007): "La publicidad disfrazada o el pseudoperiodismo". En Estudios sobre el mensaje periodístico, $\mathrm{n}^{\mathrm{o}} 13$, pp. 337-351.

DOMÍNGUEZ, Ramón J. (1853): Diccionario Nacional o Gran Diccionario Clásico de la Lengua Española (1846-47). Madrid-París, Establecimiento de Mellado.

GASPAR Y ROIG (1855): Biblioteca Ilustrada de Gaspar y Roig. Diccionario enciclopédico de la lengua española [...] Tomo II. Madrid, Imprenta y Librería de Gaspar y Roig, editores.

LUJÁN, Néstor y PERUCHO, Juan (1972): El libro de la cocina española: gastronomía e historia. Barcelona, Danae.

MARTÍNEZ LLOPIS, Manuel (1981): Historia de la gastronomía española. Madrid, Editor Nacional.

NÚÑEZ DE TABOADA, Manuel (1825): Diccionario de la lengua castellana, para cuya composición se han consultado los mejores vocabularios de esta lengua y el de la Real Academia Española, [...], 2 vols. Paris, Seguin.

PÉREZ, Dionisio (1929): Guía del buen comer español: inventario y loa de la cocina clásica de España y sus regiones. Madrid, Patronato Nacional de Turismo.

PÉREZ SAMPER, Ma de los Ángeles (2009): "La Historia de la Historia de la alimentación". Chronica Nova, 35, pp. 105-162.

REAL ACADEMIA ESPAÑOLA (1780): Diccionario de la lengua castellana compuesto por la Real Academia Española, reducido a un tomo para su más fácil uso. Madrid, Joachín Ibarra.

REAL ACADEMIA ESPAÑOLA (1852): Diccionario de la lengua castellana por la Real Academia Española. Décima edición. Madrid, Imprenta Nacional.

REAL ACADEMIA ESPAÑOLA (1869): Diccionario de la lengua castellana por la Real Academia Española. Undécima edición. Madrid, Imprenta de Don Manuel Rivadeneyra.

REAL ACADEMIA ESPAÑOLA (1925): Diccionario de la lengua española. Decimoquinta edición. Madrid, Calpe.

REAL ACADEMIA ESPAÑOLA (1970): Diccionario de la lengua española. Decimonovena edición. Madrid, Espasa-Calpe.

RODRÍGUEZ NAVAS Y CARRASCO, Manuel (1918): Diccionario general y técnico hispano-americano. Madrid, Cultura Hispanoamericana.

SAIZ, Ma Dolores (1996): "Nuevas fuentes historiográficas". Historia y comunicación social, pp. 131-143. Madrid, Servicio de Publicaciones de la Universidad Complutense. 
SALVÁ, Vicente (1846): Nuevo diccionario de la lengua castellana, que comprende la última edición íntegra, [...]. Paris, Vicente Salvá.

SEOANE, M ${ }^{\text {a }}$ Cruz (1992): Historia del periodismo en España. 2. El siglo XIX. Madrid, Alianza Universidad Textos.

SIMÓN PALMER, Ma del Carmen y ANSÓN, Rafael (1997): "Bibliografía universal de gastronomía". Cuenta y razón, no 104, pp. 123-132.

SIMÓN PALMER, $\mathrm{M}^{\mathrm{a}}$ del Carmen (1999): "Bibliofilia y gastronomía: una colección ejemplar". Pliegos de bibliofilia, n ${ }^{\circ}$ 7, pp. 27-32.

SIMÓN PALMER, Ma del Carmen (2003): Bibliografia de la gastronomía y la alimentación en España. Gijón, Ediciones Trea.

THEBUSSEM, Dr. [pseudónimo de Mariano Pardo de Figueroa] y un cocinero de SM [pseudónimo de José de Castro y Serrano] (1888): La mesa moderna cartas sobre el comedor y la cocina cambiadas entre el Doctor Thebussem y Un cocinero de S.M. Madrid, Librerías de Fernando Fe y Leocadio López y sus corresponsales.

ZEROLO, Elías (1895): Diccionario enciclopédico de la lengua castellana. París, Garnier hermanos. 